\title{
ВИРТУАЛЬНАЯ РЕАЛЬНОСТЬ КАК ПРОЯВЛЕНИЕ ОДНОЙ ИЗ ОСНОВНЫХ ФОРМ ЭСКАПИЗМА В МОЛОДЕЖНОЙ СРЕДЕ
}

\author{
Челомбицкая Марина Петровна \\ к.филос.н., доцент кафедры общзегуманитарных и естественнонаучных дисичипли \\ «Ессентукский институт управления, бизнеса и права»
}

\section{VIRTUAL REALITY AS A MANIFESTATION OF ONE OF THE MAIN FORMS OF ESCAPISM AMONG YOUNG PEOPLE}

\author{
Chelombitskaya Marina Petrovna \\ PhD in Philosophy, candidate of philosophy science, \\ the senior lecturer of chair "General humanitarian and natural-science disciplines» \\ Essentuky Institute of Management, Business and Law
}

\begin{abstract}
Аннотация. В статье рассматривается распространяющееся в молодежной среде явление - эскапизм стремление сбежать или отстраниться от реальности, погрузившись в иллюзии или интенсивную деятельность, то есть выработка новых адаптационных механизмов к социальной среде, коренным образом отличающееся от такого явления, как самовыражение личности. Эскапизм несет в себе угрозу духовному опустошению, способствует расколу ценностных ориентаций, нигилизму и ломке нравственных идеалов.

Abstract. The article examines the phenomenon of escapism, which is spreading among young people - the desire to escape or detach from reality, immersed in illusions or intense activity, that is, the development of new adaptation mechanisms to the social environment, radically different from such a phenomenon as self-expression of personality. Escapism poses a threat to spiritual devastation, contributes to the split of value orientations, nihilism and the breaking of moral ideals.
\end{abstract}

Ключевые слова: эскапизм, адаптация, молодежная среда, уход от реальности.

Key words: escapism, adaptation, youth environment, escape from reality.

Человечество живёт сегодня в быстро меняющемся мире, где порой отсутствуют надёжные точки опоры, где царят растерянность, тревога, недоверие, где свобода выбора ограничена пугающей ответственностью, где человек оказывается открытым миру, но и одиноким.

Молодое поколение порой не успевает адаптироваться к быстро меняющемуся обществу. Опыт прошлого и модернизация социума порой настолько различны между собой и настолько скоротечны, что вносят в неокрепшее сознание молодого поколения определенный диссонанс. У юных людей отсутствуют социальные ориентиры. То, что было важно для предыдущего поколения, теряет свою ценность в рамках урбанизации и модернизации современного мира. Поэтому дальнейший выбор цели и пути молодежи начинает определяться обстоятельствами и требованиями общества, а не способностями и желаниями самого индивида.

К наиболее типичным проблемам молодых людей относятся нереалистичность жизненных стремлений, рассогласованность ожиданий и реальных возможностей. Поэтому слишком часто в случае возникновения затруднений на пути к поставленной цели у них возникает такая негативная тенденция, как потребность дистанцироваться, погрузиться в мир иллюзий и фантазий. Стремлении индивида или социальной группы уйти от общепринятых образцов и стандартов жизни социума называется эскапизмом.

Эскапизм - это стремление сбежать, спрятаться или отстраниться от реальности, погрузившись в иллюзии или интенсивную деятельность. Термин «эскапизм» образован от английского слова еsсаре («бегство», «убегать»), которое знакомо каждому пользователю компьютера, поскольку в сокращенном виде присутствует на любой современной клавиатуре. В основе этого явления находится сомнение в том, насколько целесообразно и необходимо использовать существующие в обществе модели взаимодействия, следствием которого является попытка критически переосмыслить общепринятые нормы. Содержательно же эскапизм как явление сталкивается с проблемой выработки новых, отличных от предыдущих, адаптационных механизмов к социальной среде. Очень важно отличать эскапизм от эпатажа и самовыражения личности. Эпатаж, как и самовыражение личности представляют собой поведение, наущающее моральные установки и сопровождающееся эффектом непредсказуемости и неожиданности, а также настроенностью выделяться из толпы с помощью протестных форм деятельности [2]. Эскапизм же представляет собой уход от реальности, в основе которого лежат устойчивые установки личности, и он может происходить в достаточно пассивной форме, например в избегании общения, отчужденности, уходе в свой мир. Объясняя, что такое эскапизм, обычно всегда уточняют, что это попытка отстраниться от реальности, чтобы избежать какого-то дискомфорта или восполнить дефицит приятных эмоций. При этом, если копнуть глубже, то можно обнаружить, что есть 
несколько основных причин, которые встречаются чаще всего: неуверенность в себе, взаимоотношения с родителями, проблемы с учебой, неудовлетворённость личной и социальной жизнью, отсутствие смысла жизни.

Ж. Бодрийяр в своей концепции симулякра обозначил эпоху современности как эру симуляции и гиперреальности, когда человек отчужден от самой действительности и она подменяется ее знаками. В гиперреальности человек уже не может различать воображаемое и реальное, где размыты границы противоположных полюсов всех сфер общественной жизни. Если человек утрачивает чувство реальности, то эскапизм как уход в виртуальную среду (гиперреальность) становится повседневным и типичным способом существования человека. Эскапизм приводит к эффекту депривации, при котором начинает возникать состояние социальной изоляции. Такой эффект возникает тогда, когда только близкие люди допускаются к взаимодействию, так как есть уверенность, что они не нанесут вреда [3].

В современном мире изоляция чаще наблюдётся у молодых людей, склонных к девиантному поведению и различным формам его проявления.

Формы проявления эскапизма бывают разными. Человек может погружаться в книги, фильмы, сериалы, телевизионные шоу и компьютерные игры. Иногда эскапизм проявляется в более активных и часто весьма продуктивных занятиях, таких как спорт, рукоделие, творчество и всевозможные хобби. Но часто подоплекой всего этого выступает так называемая «псевдодеятельность», дающая человеку ощущение движения, но не ведущая ни к какому результату и не выводящая его из зоны комфорта.

К со временным формам эскапизма можно отнести следующие: Религиозный, субкультурный и социальный. Религиозный эскапизм рассматривается как стремление объяснить происходящие события предопределенностью высшими силами, вера в наличие особой среды, где можно отстраниться от переживаний и стрессов обыденной жизни, погрузиться во внутренний мир. При религиозном эскапизме человек кардинально меняет прошлую жизнь, полностью погружаясь в квазикультурное пространство.

Субкультурный эскапизм представляет собой явление, проявляющееся в попытке личности найти узкую группу единомышленников, объединенную общим стремлением создать иллюзорный мир, погрузиться в него и максимально абстрагироваться от реалий. Такое поведенческая стратегия приводит впоследствии к социальной изоляции, отсутствию реального социального опыта и адаптационным нарушениям.

Социальный эскапизм как неприятие существующей социальной системы выражается в устойчивой ориентации на выход из этой системы. Самым распространенным выходом является виртуальная реальность как новое жизненное пространство и рассматривается как негативная социальная тенденция, опасная тем, что личность перестает нуждаться в социальных контактах, утрачивает базовые коммуникативные умения и возможность самореализации в реальном мире [4].

В виртуальной культуре развиваются те же проблемы, что и в реальном мире: несправедливость, игромания, преступность, вседозволенность, рост социального неравенства, которые переносятся в социальные сети, интернет-сообщества. Виртуальная реальность активно воздействует на современное общество, вовлекая наиболее восприимчивую его часть - молодежь.

Именно эта группа общества подвержена глубокому погружению в различные формы виртуальной реальности. Если у молодого человека не удовлетворены какие-то из базовых потребностей, согласно А. Маслоу [8], он находит утешение в мире онлайн-игры, где у него будет высокий уровень и самое дорогое оружие, а его имя будет занимать верхние строчки в игровом рейтинге. Либо он может проводить время в социальных сетях, где для всех будет выглядеть успешным и счастливым, потому что публикует там свои лучшие фотографии.

Особенность обеих описанных выше ситуаций заключается в том, что человек не только изображает из себя успешную личность, но и в действительности ощущает себя успешным. Приходя вечером домой и заходя в игру или в соцсеть, он полностью погружается в этот мир, отвлекается от жизненных проблем и наслаждается значимостью своих виртуальных достижений.

Сетевая коммуникация, благодаря таким чертам, как анонимность, невидимость, безопасность, дает возможность человеку создавать сетевую идентичность по своему выбору, достигая желаемого в виртуальной самопрезентации и управляя впечатлениями о себе.

Виртуальность, предназначенная для игр, на самом деле становится новой реальностью и существенным фактором жизнедеятельности «человека играющего». А виртуальная коммуникация объективно становится все более плодотворной формой самореализации человека.

Тонкая грань, существующая между безобидным развлечением и зависимостью от компьютерной игры, размыта. Зависимый от игры человек, погружается в виртуальную жизнь не желая решать реальные проблемы. В игре он полон сил, он бесстрашен и вооружен. Человек начинает ощущать себя успешным, защищенным и уверенным в себе, но увы, это только лишь виртуально. «Выныривая» в реальность, он начинает ощущать себя все тем же маленьким никчемным человечком, таким беззащитным перед окружающей его агрессивной средой. Ведь часы, проведенные в игре, к сожалению, не делают его успешнее и сильнее в реальности. И он снова и снова возвращается к той жизни в которой он герой и победитель. Таким образом зарождается психологическая зависимость от компьютерных игр. Со временем уходит на второй план семья, учеба, чувства, адекватные желания и потребности. Человека буквально «затягивает» в виртуальный мир и самым важным в его жизни 
становится одно - это игра. Игроманы могут часами проводить время за компьютером, не замечая ничего и никого вокруг [5].

В первую очередь в группу риска попадают подростки жаждущие самостоятельности. Уставшие от бесконечного контроля и нравоучения взрослых, они «бегут без оглядки» в виртуальный мир. Еще совсем недавно создатели компьютерных игр были ориентированы именно на детей подросткового возраста, но на сегодняшний день прогрессирующими темпами увеличивается число взрослых людей, зависимых от игры [6].

Также зависимости от компьютерных игр подвергаются молодые люди с низкой самооценкой, эмоционально неустойчивые, закомплексованные и имеющие недостаток внимания, зачастую имеющие проблемы в общении и не ощущающие себя социально значимыми.

У молодых людей сегодня появилась также возможность виртуализации человеческих отношений и межкультурных контактов. Например: сайты виртуальных знакомств, сайты виртуальных бракосочетаний, сайты виртуальных частных галерей, сайты виртуальных друзей, сайты виртуальных музыкальных групп. С позиций психологии необходимо отметить, что виртуальность позволяет многим замкнутым молодым людям заводить друзей, обмениваться информацией и вести виртуальную полноценную жизнь.

Каждый может вступить в беседу и никто не знает, кто сейчас из собеседников с тобою в контакте. Конкретной темы разговора обычно не существует, так как диалог состоит из отдельных фрагментов, не имеющей единой логической линии. Видимость общения в чате привлекательна именно своей иллюзорностью, поскольку интернет-общение не требует интеллектуальных усилий; социальные сети демократичны и не имеют никаких цензов (по возрасту, по полу, по образованию, по интересам); в виртуальном мире не встречается подлинных личностей, поэтому в нем можно выплеснуть свое «подсознание»; в мире интернета имеются все возможности виртуального бытия, можно надеть любую маску и играть любую роль; виртуальное пространство удовлетворяет потребность людей быть вместе. Он становится местом «виртуальной тусовки», своеобразного коллектива без острых углов.

Однако, позитивная роль Интернет сочетается с нежелательными последствиями информатизации. В частности, синдром Интернет-зависимости приводит к социальной изоляции, частичному или полному отказу от общения с другими людьми, разрыву дружеских связей, ослаблению эмоциональных реакций, существенному сужению сферы интересов.

Современное общество переживает бум виртуализации. Почти всю информацию человек воспринимает через виртуальную призму. Учитывая, что виртуальная реальность поглощает сознание, осуществляя его программирование, восприятие информации в таком случае носит пассивный характер. Человеку подается виртуализированная, а значит, в какой-то степени упрощенная, представленная под нужным углом, информация. Индивидуум, вынужденный жить в этом порожденном мире, впадает во все большую степень зависимости от него. Будучи встроенным в технологические и информационные процессы, человек все меньше оказывается способным влиять на их ход, но все больше начинает подчиняться законам их развития.

На наш взгляд, мир виртуальной реальности для молодого поколения, безусловно, опасен. В нем создается соблазн и реальная возможность управления психикой человека - целенаправленное манипулирование его сознанием. При уходе в виртуальную реальность у молодых людей стирается грань между реальным и виртуальным миром. Целью технологий виртуальных реальностей является создание ложного мира, но когда в сознании человека эти ложные миры станут действительными, человек просто не сможет справиться с их разделением и легко сможет произойти раздвоение личности.

Погружение человека в мир виртуальной реальности позволяет осуществлять внушение и программирование и навязывать человеку определенные поведение, образ жизни, мышление. Духовное опустошение, бесперспективность дальнейшей жизни, раскол ценностных ориентаций, распространяющийся нигилизм и ломка нравственных идеалов - вот к чему в итоге может привести уход от действительности в виртуальную реальность.

\section{Литература:}

1. Банщиков А.В. Социальные сети и интернет в социально личностном контексте // Credo new, 2018 №4 C. $115-122$

2. Белов В.И. Эскапизм: причины, функции и границы / В.И. Белов // Инновационная наука. - 2017. - № 03-1. - С. 270-276.

3. Бодрийяр Ж. Символический обмен и смерть. М.:Добросвет 2007, 387 с.

4. Греков М.А. Феномен эскапизма в медианасыщенном обществе: дис. ... канд. филос. наук: 090013 / М.А. Греков. - Омск. - 2008. - 131 с.

5. Колотова О.В. Эскапизм: опасность «бегства» в контексте психосоциальной незрелости и готовности к экстремизму / О.В. Колотова // Общество: социология, психология, педагогика. -2018. - № 12. - С. $195-198$.

6. Корниенко Т.В. Культура досуга современной молодежи. Проблемы и перспективы развития // Вестник КазГУКИ. 2016. № URL: https:/cyberleninka.ru/article/n/kultura-dosuga-sovremennoy-molodezhi-problemy-iperspektivy-razvitiya (дата обращения: 22.04.2020). 
7. Литинская Д.Г. Типы современного эскапизма и феномен экзистенциального эскапизма / Д.Г. Литинская // Ярославский педагогический вестник. - 2012. - № 1. - Том I (Гуманитарные науки). C. 308-311.

8. Маслоу А.Г. Мотивация и личность / Пер. с англ. А.М.Татлыбаевой. СПб.: Евразия, 1999. 478 с.

9. Молодежь говорит о своих особенностях и о трудностях в жизни. URL: https://fom.ru/Obraz-zhizni/12832 (дата обращения: 22.04.2020).

10. Окладникова Е.А Социальный эскапизм современной российской городской молодёжи: факторы, практики, следствия / Е.А. Окладникова // Вестник Нижегородского университета им. Н.И. Лобачевского. Серия: Социальные науки. - 2014. - № 3(35). - С. 74-83.

11. Рябов В.Б. Эскапизм и субъективное качество жизни [Электронный ресурс] / В.Б. Рябов // Институт психологии Российской академии наук. Социальная и экономическая психология. - 2017. -Т.2. - №1. - С. 44-65. Режим доступа: http://soceconom-psychology.ru/engine/documents/ document314.pdf

12. Труфанова Е.О. Эскапизм: бегство в поисках смысла / Е.О. Труфанова // Психология и Психотехника. 2014. - № 6. - С. 597-608.

13. Фетискин Н.П., Козлов В.В., Мануйлов Г.М. Социально-психологическая диагностика развития личности и малых групп / Н.П. Фетискин, В.В. Козлов, Г.М. Мануйлов. - М., 2002. - 132 с.

14. Шапинская Е.Н. Эскапизм в пространстве массовой культуры / Е.Н. Шапинская // Ярославский педагогический вестник. - 2019. - № 1(106). - С. 180-185.

\section{INFORMATION SOURCES}

1. Banshchikov A.V. Social networks and the Internet in a socio-personal context // Credo new, 2018 No. 4 pp. $115-122$

2. Belov V.I. Escapism: causes, functions and boundaries / V.I. Belov // Innovative science. - 2017. No. 03-1. - pp. 270-276.

3. Baudrillard J. Symbolic exchange and death. Moscow: Dobrosvet 2007, 387 p.

4. Grekov M.A. The phenomenon of escapism in a media-saturated society: dis. ... cand. philos. Sciences: 090013 / M.A. Grekov. - Omsk. - 2008. - 131 p.

5. Kolotova O.V. Escapism: the danger of "flight" in the context of psychosocial immaturity and readiness for extremism / O.V. Kolotova // Society: sociology, psychology, pedagogy. -2018. - No. 12. - pp. 195-198.

6. Kornienko T.V. Leisure culture of modern youth. Problems and prospects of development // Bulletin of KazGUKI. 2016. URL No.: https://cyberleninka.ru/article/n/kultura-dosuga-sovremennoy-molodezhi-problemy-iperspektivy-razvitiya (accessed: 04/22/2020).

7. Litinskaya D.G. Types of modern escapism and the phenomenon of existential escapism / D.G. Litinskaya // Yaroslavl Pedagogical Bulletin. - 2012. - No. 1. - Volume I (Humanities). - pp. 308-311.

8. Maslow A.G. Motivation and personality / Translated from the English by A.M.Tatlybaeva. St. Petersburg: Eurasia, 1999. $478 \mathrm{p}$.

9. Young people talk about their peculiarities and difficulties in life. URL: https://fom.ru/Obraz-zhizni/12832 (accessed: 04/22/2020).

10. Okladnikova E.A. Social escapism of modern Russian urban youth: factors, practices, consequences / E.A. Okladnikova // Bulletin of the Nizhny Novgorod University named after N.I. Lobachevsky. Series: Social Sciences. 2014. - № 3(35). - Pp. 74-83.

11. Ryabov V.B. Escapism and subjective quality of life [Electronic resource] / V.B. Ryabov // Institute of Psychology of the Russian Academy of Sciences. Social and economic psychology. - 2017. -Vol.2. - No. 1. - pp. 44-65. - Access mode: http://soceconom-psychology.ru/engine/documents/ document314.pdf

12. Trufanova E.O. Escapism: flight in search of meaning / E.O. Trufanova // Psychology and Psychotechnics. 2014. - № 6. - C. 597-608.

13. Fetiskin N.P., Kozlov V.V., Manuilov G.M. Socio-psychological diagnostics of personality development and small groups / N.P. Fetiskin, V.V. Kozlov, G.M. Manuilov. - M., 2002. - 132 p.

14. Shapinskaya E.N. Escapism in the space of mass culture / E.N. Shapinskaya // Yaroslavl Pedagogical Bulletin. - 2019. - № 1(106). - Pp. 180-185. 